\title{
Synergistic effects of ivabradine and metformin in the treatment of concomitant chronic heart failure and diabetes mellitus by regulating the activity of the H19/miR-423-5p/HCN4 axis
}

\author{
Type \\ Research paper

\section{Keywords} \\ diabetes mellitus, metformin, chronić heart failure, ivabradine, H19, miR-423-5p, HCN4
}

\begin{abstract}
Introduction

In this study, the molecular mechanisms underlying the therapeutic effect of metformin (MET) and ivabradine (IBD) in the treatment of concomitant chronic heart failure (CHF) and diabetes mellitus (DM) were investigated.
\end{abstract}

\section{Material and methods}

Basic and cardiac indexes were measured to study the therapeutic effect of MET and IBD. Real-time PCR, IHC assays, in-silicon analysis, luciferase assays, real-time PCR and Western blot assays were conducted to clarify the molecular mechanisms underlying the interaction between MET and IBD.

\section{Results}

MET administration restored the normal values of general/cardiac indexes in CHF rats. The abnormal values of echocardiographic indexes in CHF rats with STZ-induced DM were all corrected by a certain degree after the MET administration. Moreover, the injection of STZ up-regulated the expression of plasma NE/BNP-45, while the IBD administration reduced the levels of NE/BNP-45 in $\mathrm{CHF}$ rats. Furthermore, the administration of MET also reduced the NE level in CHF rats, indicating that both MET and IBD can exert a therapeutic effect on CHF rats. Additionally, in-silicon analysis and luciferase assays verified the role of $\mathrm{H} 19$ and $\mathrm{HCN} 4$ as target genes of miR-423-5p. In fact, the transfection of MET or $\mathrm{H} 19$ siRNA1/2 into HL-1 and $\mathrm{H} 9 \mathrm{C} 2$ cells down-regulated the levels of $\mathrm{H} 19$ and HCN4 while increasing the level of miR-423-5p.

\section{Conclusions}

MET reduces $\mathrm{H} 19$ expression via inducing methylation of its promoter, and the inhibited $\mathrm{H} 19$ expression suppresses HCN4 expression by up-regulating miR-423-5p expression. As a result, the suppressed expression of HCN4 reduces heart rate and exhibits a therapeutic effect in the treatment of concomitant $\mathrm{CHF}$ and DM. 
1 Synergistic effects of ivabradine and metformin in the treatment of concomitant 2 chronic heart failure and diabetes mellitus by regulating the activity of the H19/miR-

$3 \quad 423-5 p / H C N 4$ axis

4 Fang Zhang ${ }^{1 *}$, Weijun Jiang ${ }^{1}$, Yating Liu ${ }^{1}$, Liu Li ${ }^{1}$, Rui Wang ${ }^{2}$, Yang $\mathrm{Li}^{3}$

5 1. Ultrasound Diagnosis Department II, The First Hospital of Qinhuangdao

6 2. Endocrinology Department I, The First Hospital of Qinhuangdao

7 3. Research Department, The First Hospital of Qinhuangdao

8 Correspondence to: Fang Zhang, Ultrasound Diagnosis Department II, The first hospital

9 of Qinhuangdao, No.258 Wenhua Road, Haigang District, Qinhuangdao 066000, Hebei

10 Province, China; Email: heartsung@yeah.net

11 Abstract

12 Aims: As a type of frequently diagnosed heart disease, chronic heart failure (CHF) is 13 featured by a high incidence of mortality and morbidity. Previous studies have shown 14 that ivabradine (IBD) could exert a therapeutic effect in CHF patients, and that the 15 presence of diabetes mellitus (DM) may reduce the therapeutic effect of IBD in the 16 treatment of CHF. Moreover, metformin (MET) was shown to induce the methylation of $17 \mathrm{H} 19$, which may enable MET to function as a sensitizer of IBD in the treatment of CHF, 18 especially in those with DM. Therefore, in this study, we investigated the molecular mechanisms underlying the therapeutic effect of MET and IBD in the treatment of CHF

20 and DM. Methods: SD rat models groups were established as a CHF + streptozotocin 21 (STZ) + MET group, a CHF + IBD group, a CHF + STZ + IBD group, and a CH + STZ + IBD + 22 MET group, with 20 rats in each group. Basic and cardiac indexes were measured to 23 study the therapeutic effect of MET and IBD via transthoracic echocardiography. Real24 time PCR, ELISA, immunohistochemistry (IHC) assays and Western blot assay were 25 conducted to observe the expressions of H19, miR-423-5p, NE, BNP-45 and HCN4. In26 silicon analysis and luciferase assays were further conducted to establish the signaling 27 pathway and clarify the molecular mechanisms underlying the interaction between MET 28 and IBD. Results: MET administration restored the normal values of general/cardiac 
29 indexes in CHF rats. The abnormal values of echocardiographic indexes in CHF rats with

30 STZ-induced DM were all corrected by a certain degree after the MET administration.

31 Moreover, the injection of STZ up-regulated the expression of plasma NE/BNP-45, while

32 the IBD administration reduced the levels of NE/BNP-45 in CHF rats. Furthermore, the

33 administration of MET also reduced the NE level in CHF rats, indicating that both MET

34 and IBD can exert a therapeutic effect on CHF rats. Additionally, in-silicon analysis and

35 luciferase assays verified the role of $\mathrm{H} 19$ and HCN4 as target genes of miR-423-5p. In

36 fact, the transfection of MET or H19 siRNA1/2 into HL-1 and H9C2 cells down-regulated

37 the levels of $\mathrm{H} 19$ and HCN4 while increasing the level of miR-423-5p. Conclusions: MET

38 reduces $\mathrm{H} 19$ expression via inducing methylation of its promoter, and the inhibited $\mathrm{H} 19$

39 expression suppresses HCN4 expression by up-regulating miR-423-5p expression. As a

40 result, the suppressed expression of HCN4 reduces heart rate and exhibits a therapeutic

41 effect in the treatment of concomitant CHF and DM.

42 Running title: MET improves therapeutic effect of ivabradine

43 Key word: chronic heart failure, diabetes mellitus, ivabradine, metformin, H19, miR-423-

$445 p, \mathrm{HCN} 4$

45 Introduction

46 As a type of frequently diagnosed heart disease, chronic heart failure (CHF) is featured

47 by a high incidence of mortality and morbidity [1]. Currently, about $2 \%$ of adults in

48 Western countries suffer from CHF, while the prevalence of CHF rises above $10 \%$ in

49 patients older than 70 years [2]. Although significant progress has been made in the

50 treatment of CHF along with a decreased period of hospitalization required for many

51 CHF patients, an European Society of Cardiology Heart Failure (ESC-HF) pilot study

52 conducted in Europe showed that the 12-month mortality among hospitalized CHF

53 patients was still as high as about 20\% [3]. In addition, the prevalence of CHF increases

54 over growing age and the presence of chronic diseases, including type 2 diabetes

55 mellitus (T2DM), obesity, and hypertension [4]. Moreover, due to the current epidemic

56 of obesity and diabetes, the incidence of CHF also increases gradually in recent years [5]. 
57 Hyperpolarization-activated cyclic nucleotide-gated ( $\mathrm{HCN}$ ) ion channels, coded by HCN 58 1-4 genes, are responsible for the generation of hyperpolarization-activated current. 59 Contain four isotypes, the HCN family can modulate synaptic integration and intrinsic neuronal excitability [6, 7]. In addition, the presence of cyclic Adenosine 61 monophosphate (CAMP) can induce the activation of HCN channels [8]. Therefore, the 62 activation of HCN channels is increased by cAMP-coupled receptors. In particular, 63 among the four members of the HCN family, HCN4 shows the highest affinity for cAMP [9]. Moreover, gene microarrays have implicated the upregulation of HCN4 expression 65 in the impairment of human ventricular functions [10]. For example, it was suggested that the upregulation of HCN4 expression in the atrial tissues contributes to the

67 elevated level of atrial ectopic-beat upon atrial dilation. Therefore, potential inhibitors of HCN channels, including ivabradine (IBD) and zatebridine, may be used in the clinical treatment of CHF-induced atrial tachyarrhythmias [11].

As a specific inhibitor of HCN channels located in cardiac pacemaker cells [12], IBD can lead to a reduced level of heart rate during both exercise and resting states, without exerting any effect on blood pressure and cardiac contractility [13]. In fact, IBD was shown to exert a therapeutic effect in CHF patients by affecting the remodeling of left ventricle [14, 15]. Moreover, it was revealed that IBD enhances cardiac functions by restoring the uptake-1 of norepinephrine (NE) via specific signaling pathways, thus decreasing the elevated levels of BNP-45 and NE in CHF [16]. Other findings suggested that the activity of IBD is inhibited in diabetic hyperglycemia, potentially caused by the 78 impaired uptake-1 of NE [16].

Multiple classes of non-coding RNAs, such as long non-coding RNAs (IncRNAs) and microRNAs (miRNAs), have been shown to play essential roles in the regulation of gene expression [17]. Furthermore, IncRNAs can also regulate mRNA expression by inducing its translation or degradation [17]. For example, the hypermethylation of H19 promoter

83 was found to reduce the level of H19 in both mouse and human [18, 19]. Moreover, it was shown that metformin (MET), a compound with both anti-cancer and anti-diabetic properties, reduces the expression of $\mathrm{H} 19$ by inducing the methylation of $\mathrm{H} 19$ [20]. 
86 Previous findings showed that the presence of diabetes mellitus (DM) may reduce the

87 therapeutic effect of IBD in the treatment of CHF [16]. Meanwhile, it has also been

88 shown that MET may reduce the expression of $\mathrm{H} 19$ by enhancing the methylation status

89 of H19 promoter, which subsequently promotes the expression of miR-423-5p and

90 suppresses the expression of HCN4, a target of miR-423-5p [17]. Therefore, we

91 hypothesized that MET may function as a sensitizer of IBD in the treatment of CHF,

92 especially in those with DM.

93 Therefore, with respect to the fact that MET could reduce the expression of H19 and $94 \mathrm{H} 19$ could influence the expression of miR-423-5p, we assumed that MET could reduce 95 the expression of HCN4 via modulating the H19/miR-423-5p/HCN4 signaling in DM. 96 Moreover, as the effect of IBD was suppressed by DM in the treatment of CHF, we 97 therefore focused the study aim upon the possible synergistic effects of IBD and MET in 98 the treatment of concomitant CHF and DM.

\section{Materials and Methods}

100 Animal and treatment

101 A total of 180 healthy male Sprague Dawley (SD) rats with an average body weight of 102 about $200 \mathrm{~g}$ were purchased from the animal center of our institute and used in this 103 study. All rats were kept in an SPF grade animal facility with a 12-h light/dark cycle, 104 under a specific temperature $\left(18^{\sim} 22^{\circ} \mathrm{C}\right)$, relative humidity $\left(40^{\sim 0 \%}\right)$, and a noise level of $105<50 \mathrm{~dB}$, and were given ad libitum access to water and food. The rats were randomly 106 assigned into 9 groups, i.e., a control group (sham-operated healthy SD rats), a 107 streptozotocin (STZ) group, a STZ + MET group, a CHF group, a CHF + STZ group, a CHF + $108 \mathrm{STZ}+$ MET group, a CHF + IBD group, a CHF + STZ + IBD group, and a CHF + STZ + IBD + 109 MET group, with 20 rats in each group. During the experiment, the rats in the groups 110 involving MET treatment were given $250 \mathrm{mg} / \mathrm{kg}$ of MET via oral administration from day 1111 to day 18 of the experiment. In the control group, the rats were given water to replace 112 MET. The rats in the groups involving IBD treatment were given $10 \mathrm{mg} / \mathrm{kg}$ of IBD (Sigma113 Aldrich, St. Louis, MO) via daily i.p. injection after the establishment of the CHF model 
114 was completed. The rats in other groups were treated according to the procedures

115 described below. The experimental protocol and animal use plan in this study were

116 approved by the Animal Ethics Committee of our institute, while all experiments were

117 carried out in strict accordance with National Institutes of Health (NIH) guidelines.

\section{Induction of Diabetes}

119 STZ (Sigma-Aldrich, St. Louis, MO) was dissolved in saline and given to rats in a single 120 dose of $70 \mathrm{mg} / \mathrm{kg}$ via i.p. injection to induce diabetes. The presence of diabetes was

121 then confirmed 4 weeks later by the measurement of blood glucose level. A blood

122 glucose level of $>350 \mathrm{mg} / \mathrm{dl}$ was considered as the criterion for the successful modeling 123 of diabetic rats.

\section{Establishment of CHF}

125 The CHF rats were generated via coronary artery ligation. In brief, the rats were 126 anesthetized through the inhalation of a mixture of oxygen containing $5 \%$ of isoflurane.

127 Subsequently, the rats underwent left thoracotomy performed between the 4th and the 128 5th ribs. After the left ventricular wall was carefully exposed, myocardial infarction was 129 induced by permanently ligating the left anterior descending artery using a 130 polypropylene suture. In the next step, the lungs of the rats were hyper-inflated via a 131 positive end-expiratory pressure. Subsequently, the chest opening in the rats was 132 sutured and the survival of rats was monitored for $24 \mathrm{~h}$.

\section{The size of myocardial infarction and left ventricular function}

134 At about 7 weeks after the model establishment, the rats were anesthetized to measure 135 their dimensions of left ventricle and heart rate using transthoracic echocardiography. A 136 phased array transducer was used to carry out the measurements according to the 137 manufacturer's instructions. In addition, at the end of each measurement, a catheter 138 was placed in the right carotid artery of the rats to determine the arterial blood 139 pressure and the left ventricular end-diastolic pressure, the two parameters later used 140 to evaluate the cardiac functions of the rats in different groups. In terms of the size of 
141 myocardial infarction, all rats were euthanized at the end of experiment and the heart

142 of each rat was removed to estimate the size of myocardial infarction according to the

143 method described in the literature [28-31].

\section{Measurements of NE and BNP-45 by ELISA}

145 The expression of NE and BNP-45 in the rats of different groups was measured using 146 aortic blood samples, while the uptake-1 of NE was measured using the myocardium 147 tissue samples taken from healthy tissues adjacent to the infarcted tissues of stellate 148 ganglion collected from each rat. In brief, after blood samples were collected from aorta, 149 they were immediately transferred into EDTA-coated blood sampling tubes. 150 Subsequently, the levels of NE and BNP-45 in blood samples were measured using 151 corresponding ELISA kits (RapidBio Systems, Minneapolis, MN) following the instructions 152 of the manufacturer. During the measurement, the antigens were diluted at a ratio of 1 : 15320 , and each well of the ELISA plate was added with $100 \mu \mathrm{L}$ of standard diluent and then 154 incubated at $4^{\circ} \mathrm{C}$ overnight. On the next day, diluted samples and HRP-labeled substrate 155 were added into the ELISA plate and incubated in the dark at $37^{\circ} \mathrm{C}$ for $20 \mathrm{~min}$. When an 156 obvious color change occurred in the positive control, or when a slight color change 157 occurred in the negative control, the reaction in the wells was terminated by the 158 addition of $50 \mu \mathrm{L}$ of a terminating reagent. Within $20 \mathrm{~min}$, the optical density (OD) value 159 of each well was measured at a wavelength of $450 \mathrm{~nm}$ on a microplate reader 160 (SpectraMax M5, Molecular Devices, San Jose, CA). The uptake of NE in stellate ganglion 161 tissue samples was measured in a similar way after the tissue samples were 162 homogenized into a homogenate by a blender.

\section{RNA isolation and real-time PCR}

164 Total RNA was extracted from tissue and cell samples using a TRIZOL kit (Invitrogen, 165 Carlsbad, CA) in strict accordance with the kit instructions. RNA concentration was 166 determined using a spectrometer. Primers for H19, miR-423-5p, and HCN4 mRNA were 167 synthesized by Takara (Tokyo, Japan). The reverse transcription was performed using a 168 reverse transcription kit (Thermo Fisher Scientific, Waltham, MA) with reference to the 
manufacturer's instructions. The reaction conditions of reverse transcription were as

170 follows: 50 min of reverse transcription at $42^{\circ} \mathrm{C}$ followed by $5 \mathrm{~s}$ of reverse transcriptase

171 inactivation at $85^{\circ} \mathrm{C}$. The obtained cDNA was then diluted to $50 \mathrm{ng} / \mu \mathrm{L}$ for subsequent

172 real-time PCR. The amplification system of qPCR contained $25 \mu \mathrm{L}$. The real-time PCR was

173 performed on an $A B I 7900$ real-time $P C R$ instrument ( $A B I$, Foster City, $C A)$. The real-time

174 PCR conditions were as follows: pre-denaturation at $95^{\circ} \mathrm{C}$ for $4 \mathrm{~min}$, followed by 30

175 cycles of denaturation at $95^{\circ} \mathrm{C}$ for $30 \mathrm{~s}$, annealing at $57^{\circ} \mathrm{C}$ for $30 \mathrm{~s}$ and extension at $72^{\circ} \mathrm{C}$

176 for $30 \mathrm{~s}$. A total of $2 \mu \mathrm{g}$ cDNA was used as the qPCR template for each target gene, while

$177 \beta$-actin was used as the internal reference. The $2^{-\Delta \Delta C t}$ method was used to calculate the

178 relative expression of $\mathrm{H} 19$, miR-423-5p, and HCN4 mRNA. And the primer pairs used

179 were: H19-F: 5'-TGCTGCACTTTACAACCACTG-3'; H19-R: 5'-ATGGTGTCTTTGATGTTGGGC-

180 3'; miR-423-5p-F: 5'-GgCTGAGGGGCAGAGAG-3'; miR-423-5p-R: 5'-

181 GTGCAGGgtCCGAGGT-3'; HCN4-F: 5'-CCCAAGAACCTTCCCGAGTG-3'; HCN4-R: 5'-

182 GATGTCTTCCGAGGCAGAGTGA-3'.

183 Cell culture and transfection

$184 \mathrm{HL}-1$ and H9C2 cells were purchased from the Cell Bank of the Chinese Academy of

185 Sciences and cultured at $37^{\circ} \mathrm{C}$ and $5 \% \mathrm{CO}_{2}$ in a Dulbecco's modified eagle medium 186 (DMEM) (Gibco, Carlsbad, CA) containing 10\% fetal bovine serum (Gibco, Carlsbad, CA), $187100 \mu \mathrm{g} / \mathrm{mL}$ penicillin and $100 \mu \mathrm{g} / \mathrm{mL}$ streptomycin (Invitrogen, Carlsbad, CA). The cells 188 were harvested during logarithmic growth by trypsinization and then sub-cultured 1-2 189 times a week. For MET treatment, the cells were incubated with $0.5 \mu \mathrm{M}$ or $1 \mu \mathrm{M}$ of MET 190 for $48 \mathrm{~h}$ before the cells were harvested for analysis. In addition, to test the effect of $191 \mathrm{H} 19$ on the expression of miR-423-5p and HCN4, HL-1 and H9C2 cells were transfected 192 with H19 siRNA1 or siRNA2 using Lipofectamine 2000 (Invitrogen, Carlsbad, CA) in 193 accordance with the instructions provided by the manufacturer. The cells were 194 harvested at $48 \mathrm{~h}$ post transfection and used for subsequent experiments. 
196 To clarify the regulatory relationship between miR-423-5p and H19/HCN4 mRNA, an 197 online bioinformatics tool was used to locate potential binding sites of miR-423-5p in 198 H19 and the 3' UTR of HCN4 mRNA, respectively. Subsequently, the full-length of H19 as 199 well as the $3^{\prime}$ UTR of HCN4 mRNA containing the binding site of miR-423-5p was 200 amplified by PCR and cloned into a pcDNA3.1 vector (Promega, Madison, WI), 201 respectively. In addition, site-directed mutagenesis was carried out in the miR-423-5p 202 binding sites of $\mathrm{H} 19$ and the 3' UTR of HCN4 mRNA, respectively, and the mutant 203 sequences of $\mathrm{H} 19$ and the 3' UTR of HCN4 mRNA were respectively inserted into 204 pcDNA3.1 vectors to create the mutant plasmids of H19 and HCN4 mRNA. In the next 205 step, HL-1 and H9C2 cells were co-transfected with miR-423-5p and mutant/wild type of $206 \mathrm{H} 19$ or HCN4 mRNA. After $48 \mathrm{~h}$ of transfection, the cells were collected and the 207 luciferase activity of transfected cells was measured using a Dual-luciferase reporter 208 gene assay system (Promega, Madison, WI), in which both the firefly luciferase activity 209 of target genes and the Renilla luciferase activity of the internal control were measured. 210 The expression of $\mathrm{H} 19$ or HCN4 mRNA was then calculated in terms of their relative 211 luciferase activity.

\section{Western blot analysis}

213 Total protein was extracted from tissue and cell samples, resolved by $10 \%$ SDS-PAGE, 214 and transferred onto a polyvinylidene fluoride (PVDF) membrane. The membrane was 215 blocked with $5 \%$ bovine serum albumin at room temperature for $1 \mathrm{~h}$, incubated with 216 anti-HCN4 primary antibodies (ab32675, Abcam, Cambridge, MA) at $4^{\circ} \mathrm{C}$ overnight, 217 incubated with HRP-labeled IgG secondary antibodies (ab6721, Abcam, Cambridge, MA) 218 at room temperature for $1 \mathrm{~h}$, colorized by an ECL reagent, and analyzed by Image $\mathrm{J}$ 219 software to calculate the protein expression of HCN4, which was normalized to the 220 expression of $\beta$-actin.

\section{Immunohistochemistry}

222 The expression of HCN4 in tissue samples was measured using conventional 223 immunohistochemistry assays. IHC results were processed with ImageJ software. 
225 All statistical analyses were conducted using SPSS 18 software (IBM, Chicago, IL). In 226 addition, the comparisons between two groups were carried out by $t$ test, while the 227 comparisons among multiple groups were carried out by one-way analysis of variance 228 (ANOVA), following by Scheffe's test as the post hoc test. Each experiment was 229 biologically repeated in triplicate. All results were original and strictly verified for their 230 correctness. The measurement data were expressed as mean \pm standard deviation. A $p$ 231 value of $<0.05$ was considered statistically significant.

\section{Results}

\section{General/cardiac measurements of experimental rats}

234 Fig.1 illustrated the changes of general/cardiac characteristics as well as 235 echocardiographic values in the rats from the STZ, STZ+ MET, CHF, CHF+STZ, CHF+STZ+ $236 \mathrm{MET}, \mathrm{CHF}+\mathrm{IBD}, \mathrm{CHF}+\mathrm{STZ}+\mathrm{IBD}$, and $\mathrm{CHF}+\mathrm{STZ}+\mathrm{IBD}+\mathrm{MET}$ groups (20 rats/group) in 237 comparison with the values in the control group.

238 The concentrations of blood glucose (Fig.1A) did not differ significantly after the 239 induction of $\mathrm{CHF}$, while evident increases in blood glucose concentrations were 240 observed in the STZ, CHF+STZ, and CHF+STZ+IBD groups. Therefore, the body weight 241 (Fig.1B) of the rats exposed to STZ was slightly decreased. Meanwhile, body indexes, 242 including heart weight (Fig.1C), the ratio of heart weight/body weight (Fig.1D), and 243 infarct size (Fig.1E), were all increased in CHF rats regardless of STZ exposure. 244 Interestingly, the administration of MET in STZ rats, CHF+STZ rats and CHF+STZ+IBD rats 245 restored the general/cardiac characteristics of these rats to a level similar to that in the 246 control rats, CHF rats and CHF+IBD rats. In addition, the value of mean arterial pressure 247 (Fig.1F) was not significantly altered among different groups, while a decreased heart 248 rate (Fig.1G) was only observed in CHF+IBD rats. 
250 Subsequently, echocardiographic measurements were carried out to determine the 251 values of left ventricular end-diastolic dimension (LVDD), left ventricular end-systolic 252 dimension (LVSD), left ventricular fractional shortening (LVFS), left ventricular end253 diastolic pressure (LVEDP), strain rate (SR), cardiac output (CO) and cardiac index (CI) in 254 the rats from different groups. As exhibited by the results, the values of LVDD (Fig.1H), 255 LVSD (Fig.1I) and LVEDP (Fig.1K) were all increased in CHF rats compared with those in 256 the control group, while the administration of IBD decreased the values of these indexes 257 to a certain extent. In addition, all rats exposed to STZ showed higher index values 258 compared with the rats not exposed to STZ. On the contrary, the value of LVFS (Fig.1J), 259 SR (Fig.1N), CO (Fig.1O) and Cl (Fig.1P) were decreased in CHF rats compared with that 260 in the control group, while the administration of IBD evidently increased the according 261 values in CHF rats. Similarly, the rats exposed to STZ showed a lower value of LVFS, SR, $262 \mathrm{CO}$ and $\mathrm{Cl}$ compared with the rats not exposed to STZ. Finally, the administration of MET 263 in the rats exposed to STZ corrected the abnormal values of LVDD, LVSD, LVFS, LVEDP, $264 \mathrm{SR}, \mathrm{CO}$ and $\mathrm{Cl}$ to a certain extent.

\section{Levels of NE and BNP-45 in experimental rats}

266 As shown in Fig. $1 \mathrm{~L}$ and compared with that in the control rats, the level of plasma NE 267 was evidently elevated in CHF rats with or without STZ exposure, while the rats exposed 268 to STZ showed a higher level of plasma NE than the rats not exposed to STZ. In addition, 269 the CHF rats treated by IBD showed a lower level of NE than the CHF rats not treated by 270 IBD, but a higher level of NE than control rats. Additionally, the administration of MET 271 also reduced the level of NE in the rats exposed to STZ. Similarly, the level of BNP-45 272 (Fig.1M) showed a similar trend as that of NE. Therefore, the changes in general/cardiac 273 and echocardiographic indexes as well as the changes in NE and BNP-45 expression 274 indicated that MET exerted a synergistic and therapeutic effect with IBD during CHF 275 treatment. 
277 Levels of H19, miR-423-5p, and HCN4 in the rats from different groups were measured.

278 An evident decrease in the expression of H19 (Fig.2A) as well as in the mRNA (Fig.2C) 279 and protein (Fig.2D) expression of HCN, along with a significantly increased level of miR280 423-5p (Fig.2B), was observed in the STZ+ MET, CHF+STZ+ MET, and CHF+STZ+IBD+ MET 281 groups. Moreover, when observing the methylation status of H19, MET was found to 282 evidently promote H19 methylation compared with other groups (Fig.2E). In addition, 283 IHC assays observed a reduced level of HCN protein (Fig.3) in the myocardial tissues 284 collected from the rats in the STZ+MET, CHF+STZ+ MET, and CHF+STZ+IBD+ MET groups. 285 Therefore, it can be assumed that the positive effects of MET on the activity of IBD 286 during CHF treatment might be associated with the expression of H19, miR-423-5p and 287 HCN4.

\section{Association among H19, miR-423-5p and HCN4}

289 Our in-silicon analyses discovered two conserved 'seed sequences' of miR-423-5p on $290 \mathrm{H} 19$ (Fig.4A) and 3'UTR of HCN4 (Fig.4B), respectively. Subsequent luciferase assays 291 showed that the luciferase activity of HL-1 cells co-transfected with miR-423-5p and 292 wild-type H19 (Fig.4A) or HCN4 (Fig.4B) was apparently decreased, thus validating the 293 role of $\mathrm{H} 19$ and HCN4 as target genes of miR-423-5p.

\section{Molecular mechanism underlying the effect of MET in CHF treatment}

295 The levels of H19 (Fig.4C) and HCN4 mRNA (Fig.4E)/protein (Fig.4F) were evidently 296 decreased, along with a significantly increased level of miR-423-5p (Fig.4D), in HL-1 cells 297 treated with $0.5 \mu \mathrm{M}$ or $1 \mu \mathrm{M}$ MET. Similarly, the transfection of HL-1 cells by H19 siRNA1 298 or H19 siRNA2 inhibited the expression of H19 (Fig.4G) and HCN4 mRNA (Fig.4I)/protein 299 (Fig.4J), along with highly up-regulated expression of miR-423-5p (Fig.4H). In addition, 300 similar results were obtained in H9C2 (Fig.5) cells treated with $0.5 \mu \mathrm{M} / 1 \mu \mathrm{M}$ MET or H19 301 SiRNA1/2.

302 In summary, the therapeutic effect of MET in CHF treatment and the synergistic effect of 303 MET on IBD can be established by a potential molecular mechanism, in which MET 304 exerts its inhibitory effect on $\mathrm{H} 19$ expression by enhancing the methylation of $\mathrm{H} 19$ 
promoter. As a result, the inhibited $\mathrm{H} 19$ expression up-regulates the expression of miR423-5p and reduces the expression of HCN4, which in turn reduces heart rate and 307 exhibits a therapeutic effect on CHF treatment.

\section{Discussion}

309

MET has been widely used in T2DM treatment after its approval in the U.S. and U.K. in 1995 and 1958, respectively [21]. According to the guidelines published by American Diabetes Association, MET is a first-line therapy used in the treatment of T2DM [22]. By reducing the intestinal absorption of glucose, MET can promote the uptake of peripheral glucose, enhance the sensitivity of human body to insulin, and reduce the level of insulin in fasting plasma, thus resulting in a reduced level of blood glucose without causing hypoglycemia [23]. MET is also known to activate AMPK signaling and attenuate the severity of heart failure in dogs upon the induction of rapid ventricular pacing [24]. In addition, MET was found to reduce the degree of hypertrophy and fibrosis in mice subjected to chronic stress, while preserving the LV functions and promoting the survival in mice following myocardial infarction $[25,26]$.

The exposure of human ovarian and endometrial cancer cells to MET can decrease the expression of $\mathrm{H} 19$, along with simultaneously increased methylation of $\mathrm{H} 19$ promoter [27]. In addition, the inhibition of $\mathrm{H} 19$ expression by MET can activate SAHH and not only lead to DNA methylation but also induce the methylation of proteins involved in the regulation of chromatin structures [28]. In fact, the methylation of a specific gene is not only affected by the activation of DNMTs, but also by the alterations in proteins bound to chromatin [27]. In this study, an evident reduction in the expression of H19 and HCN was observed along with a significant increase in miR-423-5p expression after the administration of MET. In addition, similar results were observed in the myocardial tissues collected from experimental rats, thus validating the positive and synergistic effects of MET and IBD in the treatment of CHF, potentially by regulating the expression of H19, miR-423-5p and HCN4. 
332 Recently, the involvement of the family of HCN channels in CHF has attracted great 333 interest. HCN channels are associated with a depolarizing current known as the funny 334 current (If), which is responsible for the activity of cardiac pacemaker. So far, four genes, 335 including HCN1, HCN2, HCN3 and HCN4, have been identified as the genes encoding 336 HCN channels [29]. Among these four genes, HCN4 gene is most highly expressed in the 337 SA node of mammalian adults [30]. For example, HCN4 accounts for nearly $80 \%$ of all 338 HCN expression in human [30]. Consistent with such observation, HCN4 mutations 339 lacking the proper function of HCN4 have been implicated in inherited sinus bradycardia, 340 thus suggesting the important role of HCN4 in the maintenance of a normal sinus 341 rhythm [31]. While the global deletion of HCN4 in mice has been shown to induce 342 embryonic lethality, other studies on HCN4-deficient embryos demonstrated an 343 apparently decreased rate of cardiac contraction [32, 33]. It was also shown that as a 344 target gene of miR-423-5p, the inhibition of HCN4 expression can lead to increased 345 levels of both Nkx2.5 and miR-423-5p in the sinus node, which in turn cause bradycardia 346 [34]. In this study, we showed that the levels of H19 and HCN4 were decreased along 347 with an increased level of miR-423-5p after the transfection of MET or H19 siRNA1/2 348 into $\mathrm{HL}-1$ and $\mathrm{H} 9 \mathrm{C} 2$ cells.

349 The remodeling of HCN has been observed in both rodents and human athletes. In fact, 350 miR-423-5p was shown to contribute to training-induced bradycardia by inhibiting the 351 expression of $\mathrm{HCN} 4$ and affecting the heart rate [34]. Therefore, miR-423-5p may 352 become a therapeutic target in the treatment of sinus node dysfunction in athletes [34]. 353 As a pharmaceutical recently approved to treat chronic angina pectoris, IBD is especially 354 helpful to treat patients who have a normal sinus rhythm but cannot be treated by beta 355 blockers [35]. It was also shown that IBD can regulate If, a mixed $\mathrm{Na}+-\mathrm{K}+$ current 356 induced by hyperpolarization and regulated by the autonomic nervous system [36]. 357 Therefore, IBD can also be used to treat sinus tachycardia [37]. Moreover, IBD was 358 found to play a protective role in the management of myocardial ischemic injury [38]. In 359 fact, the beneficial value of IBD has been recognized in the treatment of chronic heart 360 failure and in the prevention of cardiovascular death [38]. In particular, IBD was shown 
361 to reduce the heart rate in a mouse model of sinus tachycardia by upregulating the

362 expression of HCN [39]. In contrary, it was shown that the long-term administration of

363 IBD in infarcted rats could partially alleviate the severity of cardiac remodeling by 364 reducing the levels of $\mathrm{HCN} 4$ and $\mathrm{HCN} 2$ expression in atrial and ventricular 365 cardiomyocytes [40]. Moreover, coronary artery diseases and diabetes are often 366 concomitant, while prior studies showed that the mortality in myocardial infarction 367 patients with diabetes is higher than that in myocardial infarction patients with no 368 diabetes $[41,42]$. In addition, the prevalence of heart failure in myocardial infarction 369 patients with diabetes is also higher in spite of optimal treatment and prompt 370 angioplasty [43]. Interestingly, a wide range of molecular and cellular processes have 371 been implicated in the dysregulation of cardiac functions in myocardial infarction 372 patients with diabetes [44]. For example, it was shown that IBD can significantly restore 373 impaired uptake-1 of NE in the sympathetic ganglion and subsequently normalize the 374 plasma level of NE in CHF rats [45]. Similarly, the effect of IBD on enhancing the uptake3751 of NE is impaired in STZ animals [16].

\section{Conclusion}

377 In summary, we observed for the first that MET can improve the therapeutic effect of 378 IBD in the treatment of concomitant CHF and DM via the H19/miR-423-5p/HCN4 axis. In 379 fact, it has been shown that the presence of DM may reduce the therapeutic effect of 380 IBD. Meanwhile, we found that MET may reduce the expression of H19 by enhancing 381 the methylation status of its promoter, which subsequently increases the expression of 382 miR-423-5p and suppresses the expression of its target, HCN4, an important player in 383 the pathogenesis of CHF.

\section{Conflict of interest}

385 None

$386 \quad$ Figure legends

$387 \quad$ Fig.1 
388 General/cardiac/echocardiographic measurements and the levels of NE/BNP-45 in the 389 rats from the STZ, STZ+ MET, CHF, CHF+STZ, CHF+STZ+ MET, CHF+IBD, CHF+STZ+IBD, 390 and $\mathrm{CHF}+\mathrm{STZ}+\mathrm{IBD}+\mathrm{MET}$ groups (* $\mathrm{P}$ value $<0.05$, vs. control group; ** $\mathrm{P}$ value $<0.05$, vs. 391 CHF group; \# $\mathrm{P}$ value $<0.05$, vs CHF+STZ group).

392 A. The concentration of blood glucose in the rats from different groups;

393 B. Body weight of rats from different groups;

394 C. Heart weight of rats from different groups;

395 D. Heart weight/body weight ratio of rats from different groups;

396 E. Infarct size of rats from different groups;

397 F. Mean arterial pressure (MAP) of rats from different groups;

398 G. Heart rate (HR) of rats from different groups;

399 H. LVDD of rats from different groups;

400 I. LVSD of rats from different groups;

401 J. LVFS of rats from different groups;

402 K. LVEDP of rats from different groups;

403 L. Level of plasma NE in rats from different groups;

404 M. Level of BNP-45 in rats from different groups;

405 N. SR of rats from different groups;

406 O. CO of rats from different groups;

407 P. Clof rats from different groups.

$408 \quad$ Fig. 2

409 Levels of H19, miR-423-5p and HCN4 mRNA/protein in rats from different groups (* $\mathrm{P}$ 410 value $<0.05$, vs. control group; ${ }^{* *} \mathrm{P}$ value $<0.05$, vs. CHF group; ${ }^{\#} \mathrm{P}$ value $<0.05$, vs 411 CHF+STZ group).

412 A. Level of $\mathrm{H} 19$ in rats from different groups;

413 B. Level of miR-423-5p in rats from different groups;

414 C. Level of HCN4 mRNA in rats from different groups;

415 D. Western blot analysis of HCN4 protein in rats from different groups; 
E. Methylation status (\%) of $\mathrm{H} 19$ in rats from different groups.

$417 \quad$ Fig.3

418 The expression of HCN4 in myocardial tissue samples of the rats from the STZ, STZ+ MET, $419 \mathrm{CHF}, \mathrm{CHF}+\mathrm{STZ}, \mathrm{CHF}+\mathrm{STZ}+\mathrm{MET}, \mathrm{CHF}+\mathrm{IBD}, \mathrm{CHF}+\mathrm{STZ}+\mathrm{IBD}$, and $\mathrm{CHF}+\mathrm{STZ}+\mathrm{IBD}+\mathrm{MET}$ groups 420 was measured using IHC assays.

$421 \quad$ Fig.4

422 Associations among H19, miR-423-5p and HCN4 in HL-1 cells

423 A. In-silicon analysis for the relationship between miR-423-5p and H19, and luciferase 424 assay of HL-1 cells co-transfected with wild-type/mutant H19 and miR-423$5 \mathrm{p} /$ control miRNA (*P value $<0.05$, vs. miRNA controls);

B. In-silicon analysis for the relationship between miR-423-5p and HCN4, and luciferase assay of HL-1 cells co-transfected with wild-type/mutant HCN4 and miR-423$5 \mathrm{p} /$ control miRNA (* P value $<0.05$, vs. miRNA controls);

C. Level of $\mathrm{H} 19$ in $\mathrm{HL}-1$ cells treated with $0.5 \mu \mathrm{M}$ or $1 \mu \mathrm{M}$ MET compared with that in untreated $\mathrm{HL}-1$ cells ( ${ }^{*}$ P value $<0.05$, vs. untreated cells);

D. Level of miR-423-5p in HL-1 cells treated with $0.5 \mu \mathrm{M}$ or $1 \mu \mathrm{M}$ MET compared with that in untreated $\mathrm{HL}-1$ cells ( ${ }^{*} \mathrm{P}$ value $<0.05$, vs. untreated cells);

E. Level of HCN4 mRNA in HL-1 cells treated with $0.5 \mu \mathrm{M}$ or $1 \mu \mathrm{M}$ MET compared with that in untreated HL-1 cells (* P value $<0.05$, vs. untreated cells);

F. Western blot analysis of HCN4 protein expressed in HL-1 cells treated with $0.5 \mu \mathrm{M}$ or $1 \mu \mathrm{M}$ MET compared with that in untreated HL-1 cells (* $\mathrm{P}$ value $<0.05$, vs. untreated cells);

G. Level of H19 in HL-1 cells transfected with H19 siRNA 1 or H19 siRNA2 compared with that in HL-1 cells transfected with the negative control $(* \mathrm{P}$ value $<0.05$, vs. untreated cells);

H. Level of miR-423-5p in HL-1 cells transfected with H19 siRNA 1 or H19 siRNA2 compared with that in $\mathrm{HL}-1$ cells transfected with the negative control (* $\mathrm{P}$ value < 0.05 , vs. untreated cells); 
444 I. Level of HCN4 in HL-1 cells transfected with H19 siRNA 1 or H19 siRNA2 compared 445 with that in HL-1 cells transfected with the negative control (* $\mathrm{P}$ value $<0.05$, vs. $446 \quad$ untreated cells);

447 J. Western blot analysis of HCN4 protein expression in HL-1 cells transfected with H19 448 siRNA 1 or H19 siRNA2 compared with that in HL-1 cells transfected with the $449 \quad$ negative control (* $\mathrm{P}$ value $<0.05$, vs. untreated cells).

$450 \quad$ Fig.5

451 Associations among H19, miR-423-5p and HCN4 in H9C2 cells.

452 A. In-silicon analysis for the relationship between miR-423-5p and H19, and luciferase 453 assay of $\mathrm{H} 9 \mathrm{C} 2$ cells co-transfected with wild-type/mutant H19 and miR-423$4545 \mathrm{p} /$ control miRNA (* $\mathrm{P}$ value $<0.05$, vs. miRNA controls);

455 B. In-silicon analysis for the relationship between miR-423-5p and HCN4, and luciferase 456 assay of $\mathrm{H} 9 \mathrm{C2}$ cells co-transfected with wild-type/mutant HCN4 and miR-423$4575 \mathrm{p} /$ control miRNA (* P value $<0.05$, vs. miRNA controls);

458 C. Level of $\mathrm{H} 19$ in $\mathrm{H} 9 \mathrm{C} 2$ cells treated with $0.5 \mu \mathrm{M}$ or $1 \mu \mathrm{M}$ MET compared with that in untreated H9C2 cells ( ${ }^{*}$ P value $<0.05$, vs. untreated cells);

D. Level of miR-423-5p in H9C2 cells treated with $0.5 \mu \mathrm{M}$ or $1 \mu \mathrm{M}$ MET compared with that in untreated $\mathrm{H} 9 \mathrm{C} 2$ cells ( ${ }^{*} \mathrm{P}$ value $<0.05$, vs. untreated cells);

E. Level of HCN4 mRNA in H9C2 cells treated with $0.5 \mu \mathrm{M}$ or $1 \mu \mathrm{M}$ MET compared with that in untreated $\mathrm{H} 9 \mathrm{C} 2$ cells (* P value $<0.05$, vs. untreated cells);

F. Western blot analysis of HCN4 protein expressed in H9C2 cells treated with $0.5 \mu \mathrm{M}$ or $1 \mu \mathrm{M}$ MET compared with that in untreated H9C2 cells (* P value $<0.05$, vs. untreated cells);

G. Level of $\mathrm{H} 19$ in $\mathrm{H} 9 \mathrm{C} 2$ cells transfected with $\mathrm{H} 19$ siRNA 1 or H19 siRNA2 compared with that in $\mathrm{H} 9 \mathrm{C} 2$ cells transfected with the negative control (* P value $<0.05$, vs. untreated cells);

H. Level of miR-423-5p in H9C2 cells transfected with H19 siRNA 1 or H19 siRNA2 compared with that in $\mathrm{H} 9 \mathrm{C} 2$ cells transfected with the negative control (* $\mathrm{P}$ value < 0.05 , vs. untreated cells); 
473 I. Level of HCN4 in H9C2 cells transfected with H19 siRNA 1 or H19 siRNA2 compared $474 \quad$ with that in $\mathrm{H} 9 \mathrm{C} 2$ cells transfected with the negative control ( $* \mathrm{P}$ value $<0.05$, vs. $475 \quad$ untreated cells);

476 J. Western blot analysis of HCN4 protein expression in H9C2 cells transfected with H19 477 siRNA 1 or $\mathrm{H} 19$ siRNA2 compared with that in $\mathrm{H} 9 \mathrm{C} 2$ cells transfected with the $478 \quad$ negative control ( $* \mathrm{P}$ value $<0.05$, vs. untreated cells).

\section{References}

$4801 \quad$ McMurray JJ, Stewart S: Epidemiology, aetiology, and prognosis of heart failure. 481 Heart 2000;83:596-602.

4822 Mosterd A, Hoes AW: Clinical epidemiology of heart failure. Heart 2007;93:1137$483 \quad 1146$.

4843 Maggioni AP, Dahlstrom U, Filippatos G, Chioncel O, Crespo Leiro M, Drozdz J, 485 Fruhwald F, Gullestad L, Logeart D, Fabbri G, Urso R, Metra M, Parissis J, Persson H, Ponikowski P, Rauchhaus M, Voors AA, Nielsen OW, Zannad F, Tavazzi L: EURObservational Research Programme: regional differences and 1-year follow-

4904 Ponikowski P, Voors AA, Anker SD, Bueno H, Cleland JGF, Coats AJS, Falk V, 491 Gonzalez-Juanatey JR, Harjola VP, Jankowska EA, Jessup M, Linde C, Nihoyannopoulos P, Parissis JT, Pieske B, Riley JP, Rosano GMC, Ruilope LM, Ruschitzka F, Rutten FH, van der Meer P: 2016 ESC Guidelines for the diagnosis and treatment of acute and chronic heart failure: The Task Force for the diagnosis and treatment of acute and chronic heart failure of the European Society of Cardiology (ESC)Developed with the special contribution of the Heart Failure Association (HFA) of the ESC. Eur Heart J 2016;37:2129-2200.

5 Mozaffarian D, Benjamin EJ, Go AS, Arnett DK, Blaha MJ, Cushman M, Das SR, de Ferranti S, Despres JP, Fullerton HJ, Howard VJ, Huffman MD, Isasi CR, Jimenez MC, Judd SE, Kissela BM, Lichtman JH, Lisabeth LD, Liu S, Mackey RH, Magid DJ, McGuire DK, Mohler ER, 3rd, Moy CS, Muntner P, Mussolino ME, Nasir K, 
Neumar RW, Nichol G, Palaniappan L, Pandey DK, Reeves MJ, Rodriguez CJ, Rosamond W, Sorlie PD, Stein J, Towfighi A, Turan TN, Virani SS, Woo D, Yeh RW, Turner MB: Executive Summary: Heart Disease and Stroke Statistics--2016 Update: A Report From the American Heart Association. Circulation 2016;133:447-454.

Biel M, Wahl-Schott C, Michalakis S, Zong X: Hyperpolarization-activated cation channels: from genes to function. Physiol Rev 2009;89:847-885.

7 Chu HY, Zhen X: Hyperpolarization-activated, cyclic nucleotide-gated (HCN) channels in the regulation of midbrain dopamine systems. Acta Pharmacol Sin 2010;31:1036-1043.

Baruscotti M, Bottelli G, Milanesi R, DiFrancesco JC, DiFrancesco D: HCN-related channelopathies. Pflugers Arch 2010;460:405-415.

14 Yue-Chun L, Teng Z, Na-Dan Z, Li-Sha G, Qin L, Xue-Qiang G, Jia-Feng L: Comparison of effects of ivabradine versus carvedilol in murine model with the Coxsackievirus B3-induced viral myocarditis. PLoS One 2012;7:e39394. 
15 Swedberg K, Komajda M, Bohm M, Borer JS, Ford I, Dubost-Brama A, Lerebours G, Tavazzi L: Ivabradine and outcomes in chronic heart failure (SHIFT): a randomised placebo-controlled study. Lancet 2010;376:875-885.

16 Cao X, Sun Z, Zhang B, Li X, Xia H: The Effects of Ivabradine on Cardiac Function after Myocardial Infarction are Weaker in Diabetic Rats. Cell Physiol Biochem 2016;39:2055-2064. acting regulatory region upstream of H19. Genes Dev 2000;14:1186-1195. Shen J, Guo M, Sun Y: Regulation of laryngeal squamous cell cancer progression by the IncRNA H19/miR-148a-3p/DNMT1 axis. Oncotarget 2016;7:11553-11566.

8 Srivastava M, Hsieh S, Grinberg A, Williams-Simons L, Huang SP, Pfeifer K: H19 and Igf2 monoallelic expression is regulated in two distinct ways by a shared cis

K awakami T, Zhang C, Okada Y, Okamoto K: Erasure of methylation imprint at the promoter and ctcf-binding site upstream of h19 in human testicular germ cell tumors of adolescents indicate their fetal germ cell origin. Oncogene 2006; 25:3225-3236.

20 Yan L, Zhou J, Gao Y, Ghazal S, Lu L, Bellone S, Yang Y, Liu N, Zhao X, Santin AD, Taylor $\mathrm{H}$, Huang $\mathrm{Y}$ : Regulation of tumor cell migration and invasion by the $\mathrm{H} 19 /$ let-7 axis is antagonized by metformin-induced DNA methylation. Oncogene 2015;34:3076-3084.

21 Scarpello JH, Howlett HC: Metformin therapy and clinical uses. Diab Vasc Dis Res 2008;5:157-167.

22 Inzucchi SE, Bergenstal RM, Buse JB, Diamant M, Ferrannini E, Nauck M, Peters AL, Tsapas A, Wender R, Matthews DR: Management of hyperglycaemia in type 2 diabetes: a patient-centered approach. Position statement of the American Diabetes Association (ADA) and the European Association for the Study of Diabetes (EASD). Diabetologia 2012;55:1577-1596. 
23 Grzybowska M, Bober J, Olszewska M: [Metformin - mechanisms of action and use for the treatment of type 2 diabetes mellitus]. Postepy Hig Med Dosw (Online) 2011;65:277-285.

24 Sasaki H, Asanuma H, Fujita M, Takahama H, Wakeno M, Ito S, Ogai A, Asakura M, Kim J, Minamino T, Takashima S, Sanada S, Sugimachi M, Komamura K, Mochizuki N, Kitakaze M: Metformin prevents progression of heart failure in dogs: role of AMP-activated protein kinase. Circulation 2009;119:2568-2577.

Xiao H, Ma X, Feng W, Fu Y, Lu Z, Xu M, Shen Q, Zhu Y, Zhang Y: Metformin attenuates cardiac fibrosis by inhibiting the TGFbeta1-Smad3 signalling pathway. Cardiovasc Res 2010;87:504-513.

Gundewar S, Calvert JW, Jha S, Toedt-Pingel I, Ji SY, Nunez D, Ramachandran A, Anaya-Cisneros M, Tian R, Lefer DJ: Activation of AMP-activated protein kinase by metformin improves left ventricular function and survival in heart failure. Circ Res 2009;104:403-411.

27 Jin B, Ernst J, Tiedemann RL, Xu H, Sureshchandra S, Kellis M, Dalton S, Liu C, Choi $\mathrm{JH}$, Robertson KD: Linking DNA methyltransferases to epigenetic marks and nucleosome structure genome-wide in human tumor cells. Cell Rep 2012;2:14111424.

Zhong T, Men Y, Lu L, Geng T, Zhou J, Mitsuhashi A, Shozu M, Maihle NJ, Carmichael GG, Taylor HS, Huang Y: Metformin alters DNA methylation genomewide via the H19/SAHH axis. Oncogene 2017;36:2345-2354. disease: consequences of sodium-calcium overload. Heart 2006;92 Suppl 4:iv1iv5.

30 Hale SL, Kloner RA: Ranolazine treatment for myocardial infarction? Effects on the development of necrosis, left ventricular function and arrhythmias in experimental models. Cardiovasc Drugs Ther 2014;28:469-475.

31 Mourouzis I, Mantzouratou P, Galanopoulos G, Kostakou E, Dhalla AK, Belardinelli L, Pantos C: The beneficial effects of ranolazine on cardiac function 
after myocardial infarction are greater in diabetic than in nondiabetic rats. J Cardiovasc Pharmacol Ther 2014;19:457-469.

32 Sossalla S, Maier LS: Role of ranolazine in angina, heart failure, arrhythmias, and diabetes. Pharmacol Ther 2012;133:311-323.

33 Brede M, Wiesmann F, Jahns R, Hadamek K, Arnolt C, Neubauer S, Lohse MJ, Hein L: Feedback inhibition of catecholamine release by two different alpha22002;106:2491-2496.

34 D'Souza A, Pearman CM, Wang Y, Nakao S, Logantha S, Cox C, Bennett H, Zhang Y, Johnsen AB, Linscheid N, Poulsen PC, Elliott J, Coulson J, McPhee J, Robertson A, da Costa Martins PA, Kitmitto A, Wisloff U, Cartwright EJ, Monfredi O, Lundby A, Dobrzynski H, Oceandy D, Morris GM, Boyett MR: Targeting miR-423-5p Reverses Exercise Training-Induced HCN4 Channel Remodeling and Sinus Bradycardia. Circ Res 2017;121:1058-1068.

35 Oeing CU, Tschope C, Pieske B: [The new ESC Guidelines for acute and chronic heart failure 2016]. Herz 2016;41:655-663.

Sulfi S, Timmis AD: Ivabradine -- the first selective sinus node I(f) channel inhibitor in the treatment of stable angina. Int J Clin Pract 2006;60:222-228.

37 Yusuf S, Camm AJ: Sinus tachyarrhythmias and the specific bradycardic agents: a marriage made in heaven? J Cardiovasc Pharmacol Ther 2003;8:89-105.

38 Fox K, Ford I, Steg PG, Tardif JC, Tendera M, Ferrari R: Ivabradine in stable coronary artery disease without clinical heart failure. $N$ Engl J Med 2014;371:1091-1099.

39 Leoni AL, Marionneau C, Demolombe S, Le Bouter S, Mangoni ME, Escande D, Charpentier F: Chronic heart rate reduction remodels ion channel transcripts in the mouse sinoatrial node but not in the ventricle. Physiol Genomics 2005;24:412.

40 Suffredini S, Stillitano F, Comini L, Bouly M, Brogioni S, Ceconi C, Ferrari R, Mugelli A, Cerbai E: Long-term treatment with ivabradine in post-myocardial 
616 infarcted rats counteracts f-channel overexpression. $\mathrm{Br} J$ Pharmacol 2012;165:1457-1466.

41 Chiha M, Njeim M, Chedrawy EG: Diabetes and coronary heart disease: a risk factor for the global epidemic. Int J Hypertens 2012;2012:697240.

42 Donahoe SM, Stewart GC, McCabe CH, Mohanavelu S, Murphy SA, Cannon CP, Antman EM: Diabetes and mortality following acute coronary syndromes. JAMA 2007;298:765-775.

43 Carrabba N, Valenti R, Parodi G, Santoro GM, Antoniucci D: Left ventricular remodeling and heart failure in diabetic patients treated with primary angioplasty for acute myocardial infarction. Circulation 2004;110:1974-1979.

44 Shi YQ, Yan M, Liu LR, Zhang X, Wang X, Geng HZ, Zhao X, Li BX: High Glucose Represses hERG K+ Channel Expression through Trafficking Inhibition. Cell Physiol Biochem 2015;37:284-296.

45 Davis D, Sinoway LI, Robison J, Minotti JR, Day FP, Baily R, Zelis R: Norepinephrine kinetics during orthostatic stress in congestive heart failure. Circ Res 1987;61:187-90. 

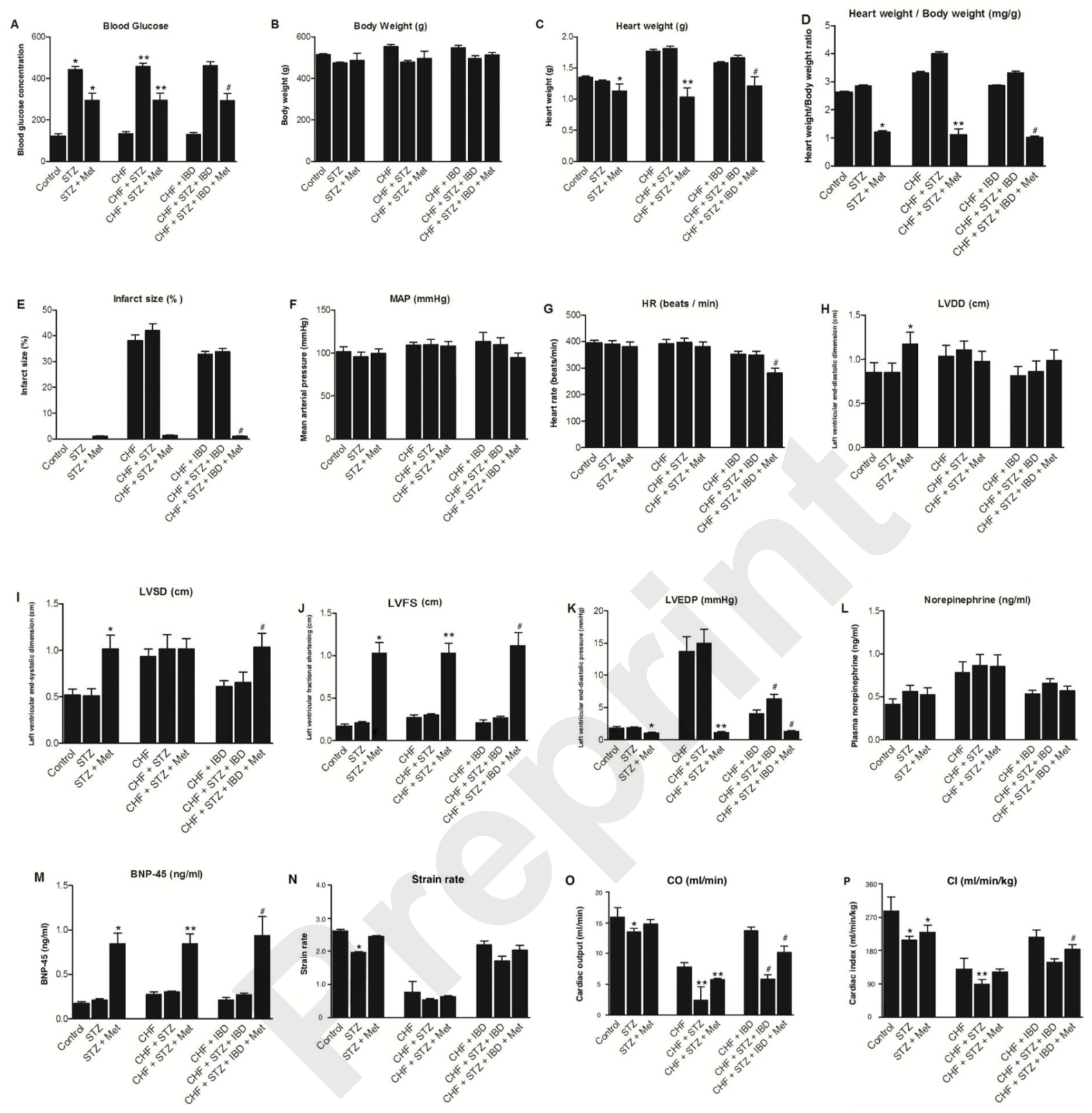

Figure 1 


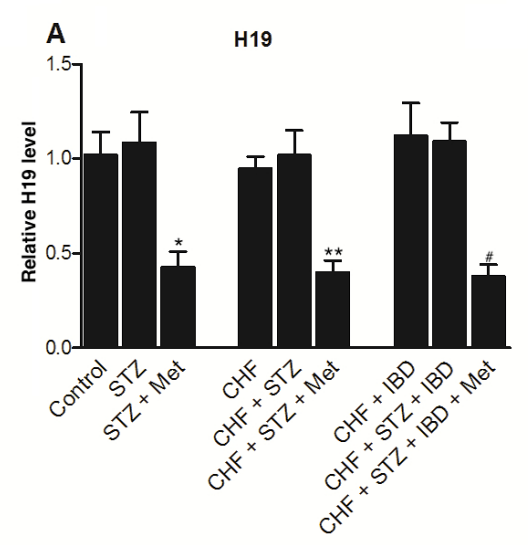

D

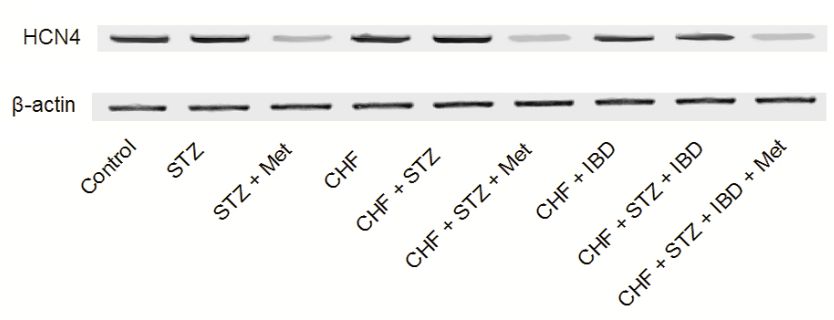

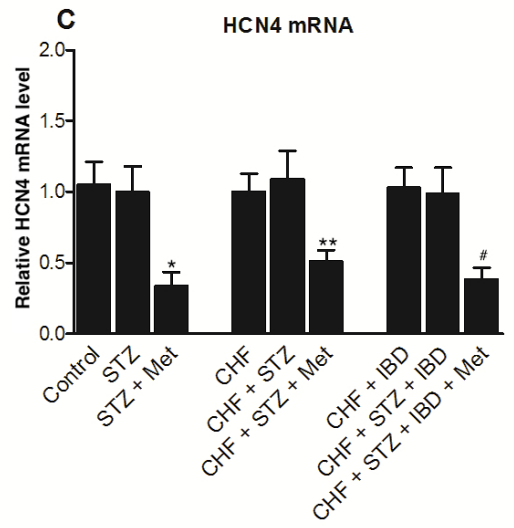

E

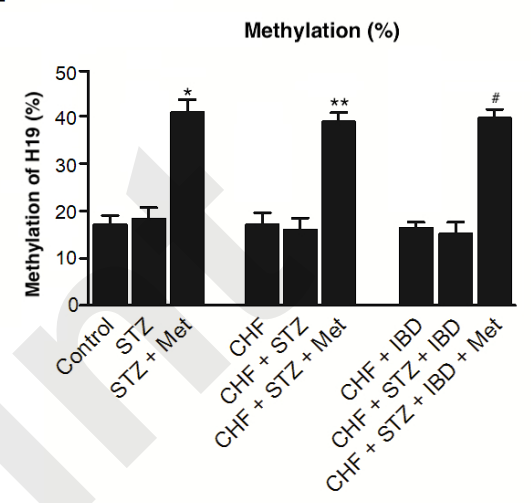

Figure 2 

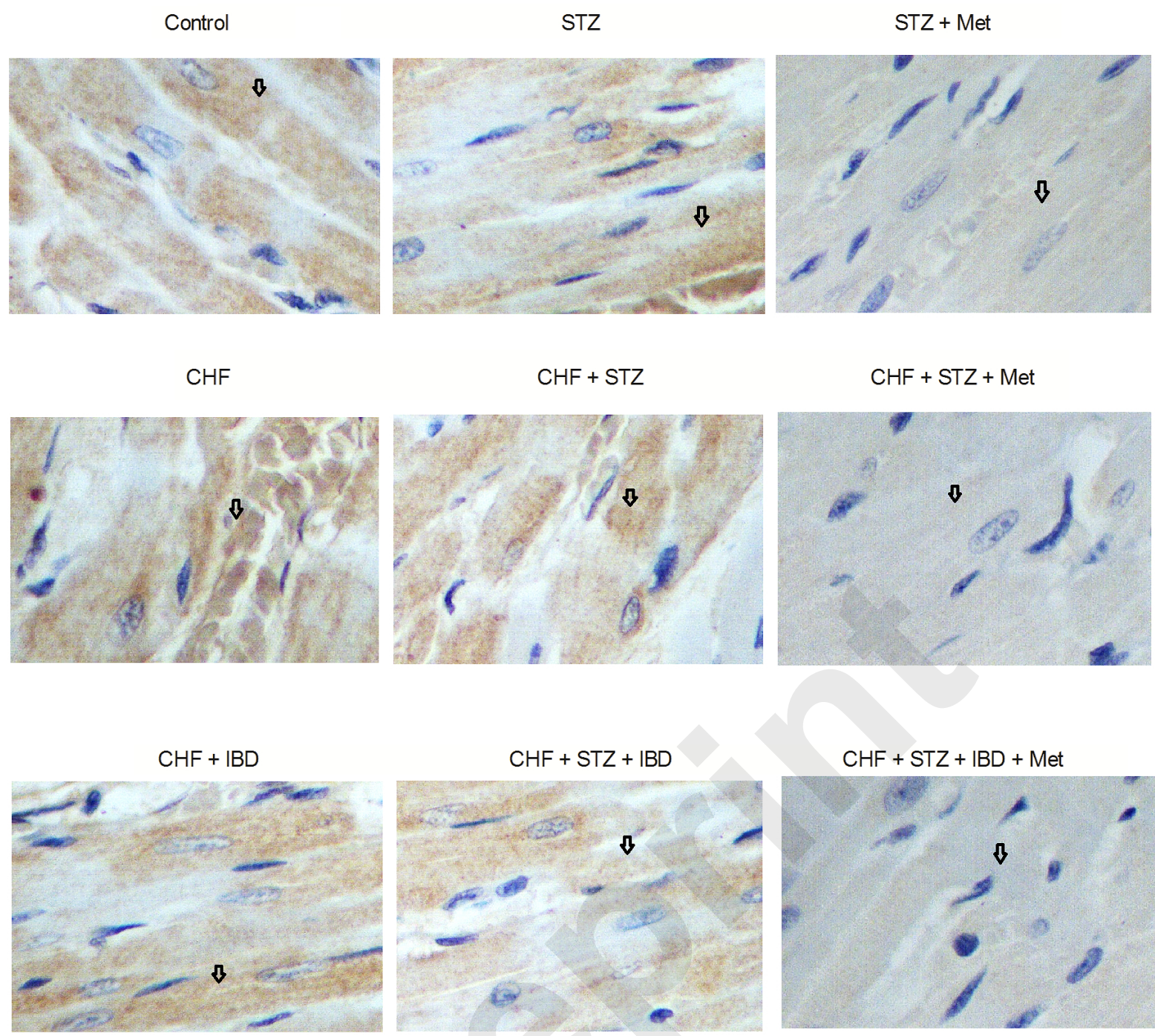

$\mathrm{CHF}+\mathrm{STZ}+\mathrm{IBD}+\mathrm{Met}$

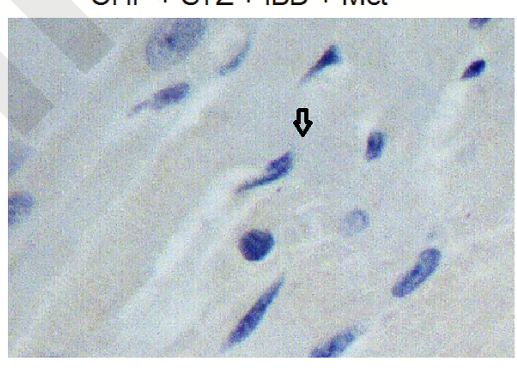

Figure 3 
A

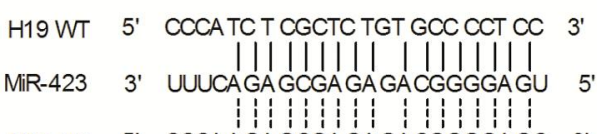

H19 MT 5' CCCAAGAGCGÁGA'GA'CGGGAGC 3'

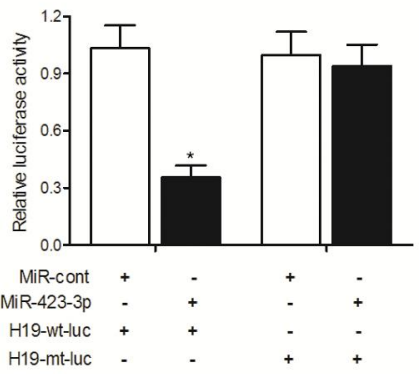

C

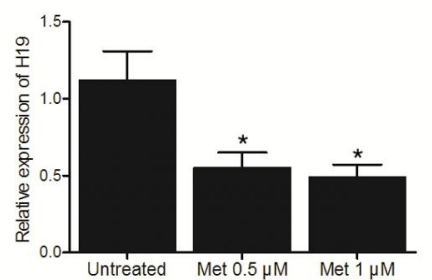

$\mathbf{F}$

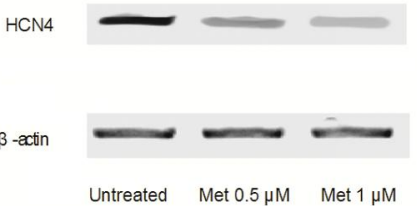

।

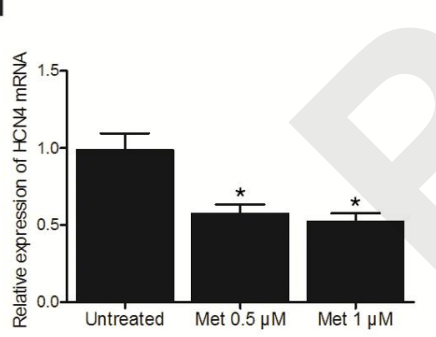

HCN4 WT 5' ACTC CCCGT CT TCTTTACACTAAAA 3'

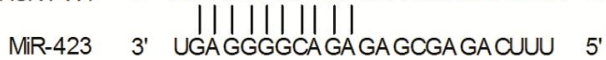
I I I I I!

HCNA MUT 5' AGÁGGGG'ÁGÁ TCTITACACTAAAA $3^{\prime}$

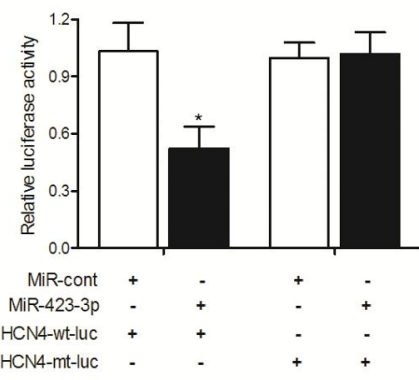

E
D

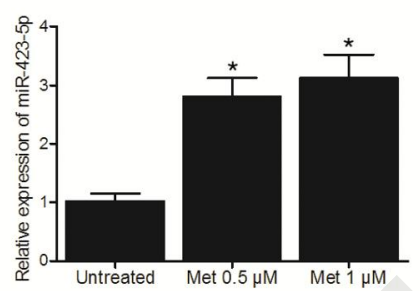

G

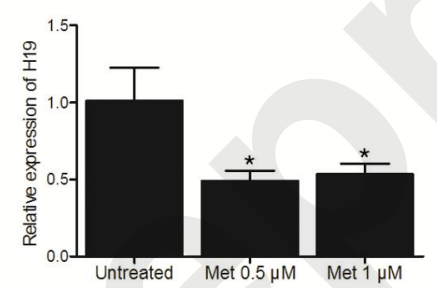

$J$

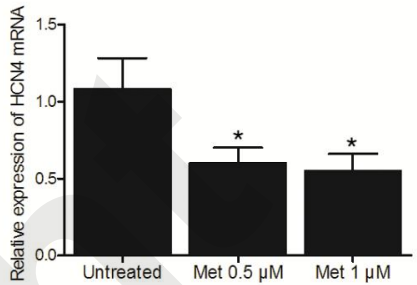

H

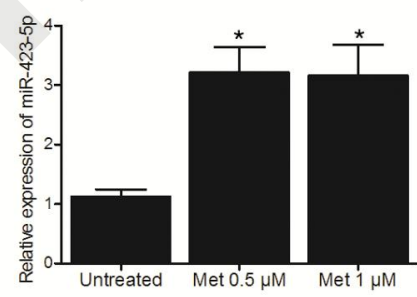

Figure 4 
A

H19 WT 5' CCCA TC T CGCTC TGT GCC CCT CC 3'

MiR-423 3' UUUCAGAGCGAGAGACGGGGAGU 5'

H19 MT 5' CCCAAGAGCGAGAGACGGGGAG 3'
HCN4 WT 5' ACTC CCCGT CT TCTTTACACTAAAA 3' $\begin{array}{lll} & \| \\ \text { MiR-423 3' UGAGGGGCAGAGAGCGAGACUUU 5' }\end{array}$

HONA MUT 5' AGÁGGGGCÁGÁ TCTITACACTAAAA

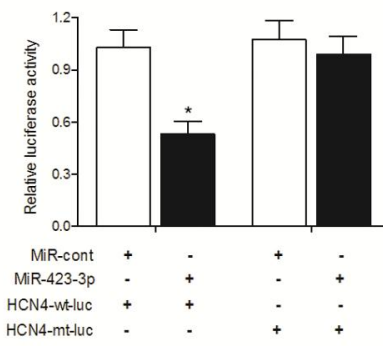

C

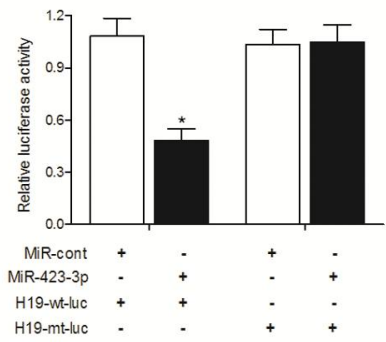

D

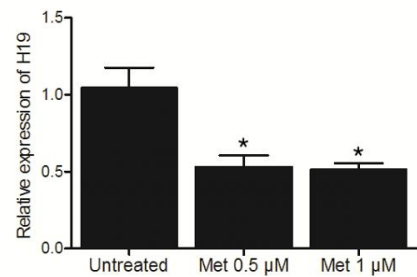

$\mathbf{F}$

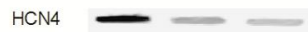

$\beta$-axtin $\longrightarrow$

Untreated Met $0.5 \mu \mathrm{M} \quad$ Met $1 \mu \mathrm{M}$

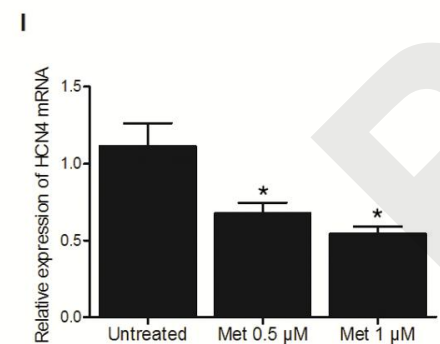

Figure 5

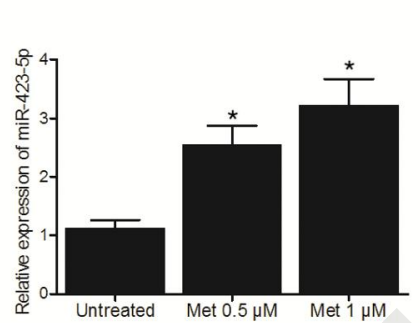

G

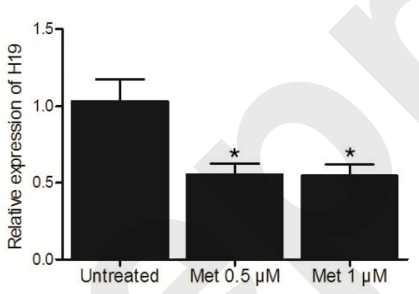

J

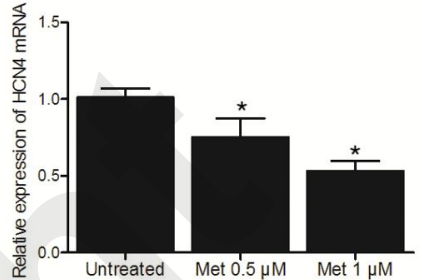

H

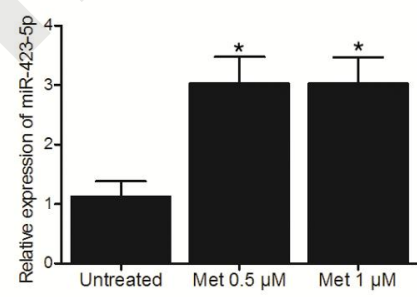

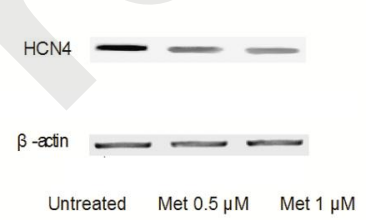

Untreated Met $0.5 \mu \mathrm{M} \quad$ Met $1 \mu \mathrm{M}$ 